\title{
Synergistic Iridium and Lewis Base Catalyzed Stereodivergent Allylic Substitutions
}

Gategory

Metal-Catalyzed Asymmetric

Synthesis and

Stereoselective

Reactions

\section{Key words}

allylic substitution

synergistic

catalysis
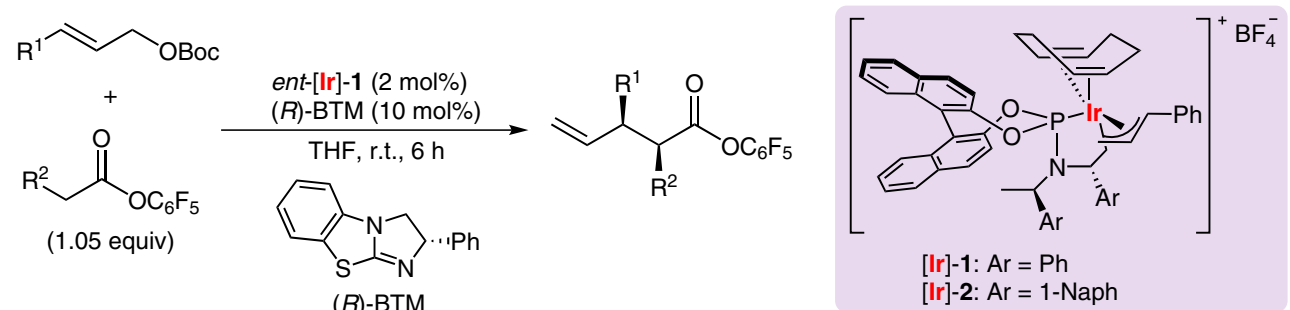

Selected examples:

(R)-BTM<smiles>C=CC(c1ccccc1)C(C(=O)OC(F)(F)F)C(=[18O])C(=O)OC(F)(F)F</smiles>

$>99 \%$ yield, $>99 \%$ ee $\mathrm{dr}=18: 1$

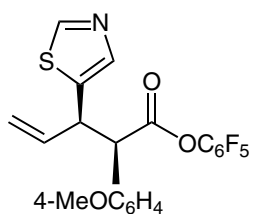

$81 \%$ yield, $>99 \%$ ee $\mathrm{dr}>20: 1$<smiles>C=CC(c1ccccc1)C(CCCC(F)(F)F)C(=O)OC(F)(F)F</smiles>

$98 \%$ yield, $>99 \%$ ee $\mathrm{dr}=17: 1^{*}$

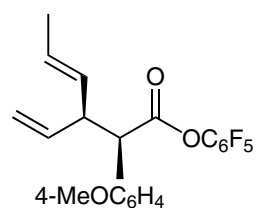

$90 \%$ yield, $>99 \%$ ee $\mathrm{dr}=17: 1$

*20 mol\% (R)-BTM was used.

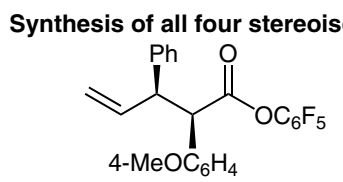<smiles>[13CH3][13CH2][13CH3]</smiles>
$\mathrm{dr}>20: 1$, branched/linear $>99: 1$

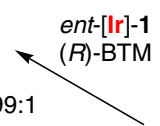<smiles>CC(C)(C)OCC/C=C/c1ccccc1</smiles>
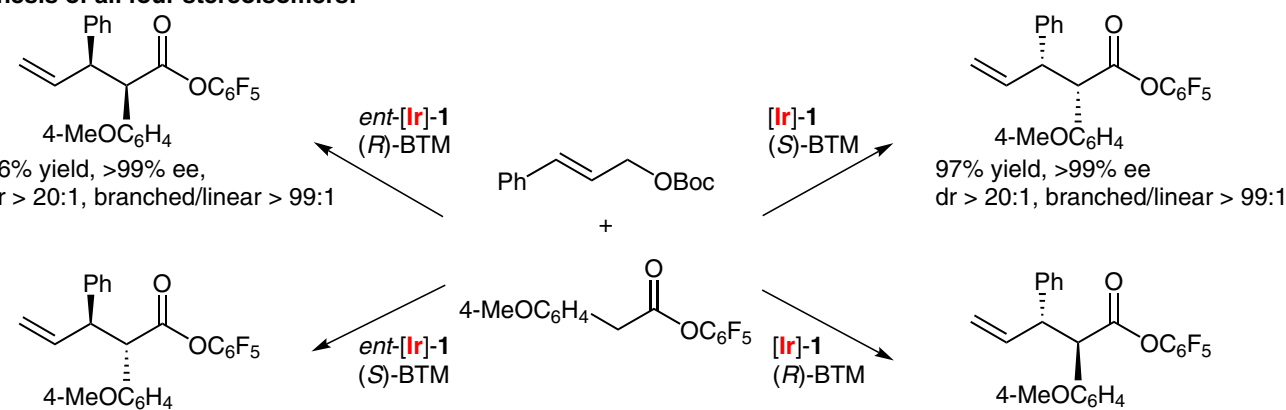

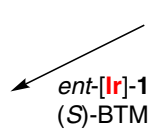

(S)-BTM

$>99 \%$ yield, $>99 \%$ ee $\mathrm{dr}>20: 1$, branched/linear $=10: 1$ iridium catalysis

Lewis bases

arylacetate esters

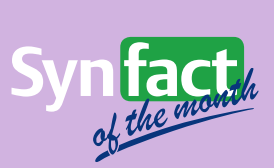

Significance: Catalytic asymmetric construction of all possible stereoisomers by a simple and unified method is a challenging research subject in synthetic organic chemistry. The authors developed a stereodivergent allylic substitution with arylacetic acid esters and synergistic iridium/ benzotetramisole (BTM) catalysis.

SYNFACTS Contributors: Hisashi Yamamoto, Hiroaki Tsuji Synfacts 2017, 13(04), 0377 Published online: 17.03.2017 Dol: 10.1055/s-0036-1590153; Reg-No.: H02317SF
Comment: The reaction proceeded in the presence of ent-[Ir]-1 and (R)-BTM as synergistic catalysts to give the corresponding products bearing two adjacent stereocenters in high yields and with excellent stereoselectivities. The catalyst system permitted the synthesis of all four stereoisomers of the products. Iridium complex [Ir]-2 also showed catalytic performance in the stereodivergent allylic substitutions. 